\title{
Natalhas Pendentes e a Vertigem narrativa de Paulo Rosenbaum*
}

\section{Navalhas Pendentes and Paulo Rosenbaum's narrative vertigo}

\author{
Christini Roman de Lima ${ }^{1}$ \\ ${ }^{1}$ Universidade Presbiteriana Mackenzie. São Paulo, SP, Brasil. \\ E-mail: christiniroman@gmail.com
}

\section{RESUMO}

Navalhas pendentes é o terceiro romance de Paulo Rosembaum e apresenta a história e os mistérios que envolvem Homero Montefiore e a indústria editorial, história essa atravessada por uma narrativa em vertigem.

PALAVRAS-CHAVE: indústria editorial; mistério; vertigem.

\section{ABSTRACT}

Navalhas pendentes is Paulo Rosembaum's third novel and presents the history and mysteries surrounding Homero Montefiore and the publishing industry, a story crossed by a narrative in vertigo.

EDITOR-CHEFE:

Rachel Esteves Lima

EDITOR EXECUTIVO:

Regina Zilberman

SUBMETIDO: 29.10 .2021

ACEITO: 05.11.2021

\section{COMO CITAR:}

LIMA, Christini Roman de. Navalhas Pendentes e a vertigem narrativa de Paulo Rosenbaum. Revista Brasileira de Literatura Comparada, v. 24 , n. 45 , p. 121-125, jan./ abr., 2022. doi: https:// doi.org/10.1590/2596$304 \times 20222445 \mathrm{crl}$

\footnotetext{
* Resenha de: ROSENBAUM, Paulo. Navalhas pendentes. Belo Horizonte: Caravana Grupo Editorial, 2021. $330 \mathrm{p}$.
} 
N avalhas pendentes é o terceiro romance do médico, poeta e escritor Paulo Rosenbaum. O autor estreou na literatura com A verdade Lançada ao Solo, publicado em 2010; em 2016 foi a vez de Céu subterrâneo, seu segundo livro. Além dos romances, publicou também $A$ pele que nos divide: diáforas continentais, livro de poemas editado em 2018. Em seu novo romance, Navalhas pendentes, Rosenbaum apresenta uma trama complexa e intrincada em que a indústria editorial é posta em cena por meio de um jogo narrativo que flerta com o nonsense.

O enredo volta-se ao protagonista Homero Arp Montefiore, ao mistério que circunda a editora em que trabalha, a Filamentos, e ao processo de fusão dessa com a "gigante emergente KGF-Foster (C)" (WALDMAN, 2015, p. 15) e o escritor best-seller Karel F. A intriga é atravessada pela memória do protagonista/ narrador e retrata o seu percurso dentro da Filamentos, sobretudo em relação ao seu envolvimento intelectual e sentimental com os romances de Karel, os acontecimentos que levaram à sua demissão e aos prováveis crimes envolvendo a editora, dos quais ele seria imputado como suspeito. Essas memórias, no entanto, são permeadas por uma doença obscura (muito provavelmente a síndrome de Marfan - responsável pela estatura elevada do protagonista e por inúmeras degenerações apresentadas ao longo da trama), fator que, aliado à narrativa fragmentária, estabelece grande imprecisão a todo o relato.

Homero Arp Montefiore tem origem judaica, fez graduação em letras, cursou especialização em editoração e em tecnologia e informação e ingressou na editora Filamentos como revisor, passando a avaliador de originais dois anos depois e, no instante da narração, trabalhara na Filamentos há mais de uma década. É como avaliador que ele tem o primeiro contato com os textos de Karel, um misterioso autor que se ocultava através desse pseudônimo e que era responsável pelo alavancamento das vendas e, consequentemente, pelo crescimento vertiginoso da editora.

A Filamentos foi criada em 1986, começara de forma modesta, mas "com faro para autores que agradavam determinados público-alvo e nichos de leitores" (p. 55). O quadro funcional, nos seus primórdios, contava com um editor-geral e alguns assistentes. A editora cresceu rapidamente e logo dobrou o número de funcionários. Um tempo depois expandiram e trocaram de sede: "do galpão do Bom Retiro para os Jardins" (p. 71), seguindo para uma luxuosa sede no Itaim Bibi. Dois anos depois, abririam filiais no Rio de Janeiro, em Porto Alegre e em Belo Horizonte. Giaccomo Gentil e sua esposa, Cleo, donos da empresa, conseguiram contratos com estatais e incentivos rentáveis com os ministérios da Educação e da Cultura. O protagonista destaca que "era evidente que Giaccomo enriquecera rapidamente. [...] O volume de dinheiro foi sedimentando uma certeza: ele vinha de múltiplas fontes. Ninguém monta um império daquele tamanho com uma única atividade” (p. 71-72).

Homero, ao longo dos dez anos de trabalho na editora, começa a suspeitar do funcionamento da empresa: "Foi numa noite insone, como tantas da minha infância, que percebi que os acontecimentos na empresa estavam muito distantes da normalidade" (p. 55). Suspeitas que o perseguem ao longo da trama, ampliando seu alcance até tomar conta do protagonista, de sua vida:

Aquele telefonema serviu para reavivar toda a paranoia. O segredo persistia. Como operavam para criar todos aqueles livros de sucesso com resultados comerciais impressionantes? Quem era Karel F., o principal autor da editora, que, pelo menos desde que comecei a trabalhar lá, nunca apareceu ou foi visto em carne e osso? Pelo menos cinco dos vinte livros mais populares do mercado editorial nos últimos dez anos foram publicados pela Filamentos. (p. 33). 
A obsessão em relação ao principal autor da editora e sua busca por decifrar a identidade dessa personagem misteriosa abalam suas relações no trabalho. $O$ narrador, mesmo rodeado de suspeitas quanto ao sucesso de vendas da editora, destaca que tudo corria bem até ser chamado para jurado no concurso mais importante do país e de Giaccomo ter exigido que ele participasse. Homero refuta por compreender se tratar de um arranjo de cartas marcadas, mas é obrigado a entrar no expediente. Diana, sua editora chefe, deixa claro: “- (...) nós, os grandes, revezamos os prêmios na mídia, no marketing, nas feiras, nas bolsas das fundações. Tudo funciona assim! Por que a literatura escaparia?” (p. 122).

Giaccomo, para expandir a Filamentos, comprava editoras menores concorrentes e, nesse processo, endividou-se a ponto de necessitar de um sócio que subsidiasse capital à empresa. A partir disso, travou-se uma busca por novas parcerias europeias. Quando a fusão com o conglomerado editorial holandês Foster Inc. estava prestes a se consolidar (processo que levou em torno de quatro anos para se estabelecer), um intrincado ardil parece recair sobre o protagonista. Como a doença que o acomete, a conspiração (ou delírio) alastra-se até deixá-lo quase sem saídas.

O romance de Paulo Rosenbaum (2021) abarca idas e vindas em relação aos fatos apresentados, idas e vindas essas que se interpõem umas às outras numa espécie de vertigem a que o leitor tem dificuldade em desenredar ou atar as pontas dos fios que tecem a trama. Esse aturdimento pode ser creditado à mente de Homero que, acometido por constantes amnésias, envolve-se ou cria uma intriga repleta de complôs que o enleiam na rede de artifícios criados, segundo o narrador, pelos mandatários da Filamentos e da Foster Inc. para incriminá-lo. O labirinto kafkiano que circunscreve as ações das personagens e, sobretudo, a forma do romance pode ser creditado à doença genética que acompanha Homero - no Processo (KAFKA, 2005), Josef K. é processado e passa por um longo processo criminal sem endender a motivação.

Navalhas pendentes principia in media res, com o incidente em que o protagonista acorda banhado em sangue e com a casa revirada. Uma dúvida passa a atormentá-lo: o sangue era seu ou era de outrem? Ele descobre um ferimento em seu pescoço que pode ser a origem da hemorragia vista por todos os cantos de seu apartamento: "Demorei alguns minutos para achar de onde brotava a mina de plasma. A nascente vinha de um pequeno talho no pescoço. Mas, e se o sangue fosse proveniente de um grande vaso ou de um aneurisma da aorta? (...) O corte de menos de dois milímetros estava em vias de cicatrizar" (p. 21).

Ao longo da trama a questão permanece e torna-se mais e mais obscura: pessoas desaparecem, um avião cai não deixando sobreviventes e o protagonista é incriminado. Com isso, o narrador estabelece indeterminações e ambiguidades: Homero é responsável pelo desaparecimento (morte?) de Giaccomo Gentil e de Jean Prada (presidente e editor-executivo da Filamentos, respectivamente)? Por que querem incriminá-lo? Qual a relação de Karel F. com o complô? Homero vivenciou tais acontecimentos ou tudo não passa de uma história criada por sua mente? Para o leitor, algumas dessas respostas ficam em aberto mesmo ao término da obra.

Coadunado aos mistérios envolvendo a indústria dos best-sellers, o incidente que dá largada ao relato pode ser pensado pelo viés do romance policial com nuances de ficção-científica - envolvendo inteligência artificial para a criação de best-sellers em escala industrial. O protagonista estaria mergulhado em intrigas que o tornariam uma peça descartável no emaranhado das relações comerciais, a que a indústria editorial não estava isenta. Nessa perspectiva, o editor da Filamentos aproximar-se-ia de Josef 
K. e da condenação inexplicável e indeterminada a que foi vítima. Como o personagem de $O$ processo, o narrador de Rosenbaum não entende ao certo porque está sendo perseguido e acusado. Não sabe ao menos se cometeu ou não algum crime. Tudo está envolto em uma bruma intransponível que turva a percepção dele e do leitor.

De outra parte, o narrador deixa pistas sobre a síndrome que carrega e sua evolução. Fatores que fazem com que todo o relato seja pensado como produto da mente desse sujeito acometido pela enfermidade que afeta não apenas sua memória, como sua consciência em vários momentos. Ele vai destacar em algumas passagens fragmentárias da trama:

Comecei a ter sintomas que meu médico diagnosticou, na falta de outra classificação, de Síndrome de Burnout, um transtorno ligado ao trabalho(...). Sentia que minha memória vagava em flashbacks cada vez mais frequentes. Lacuna de minutos transformavam-se em períodos inteiros, dias semanas. Naquela altura, eu já sabia, estava desenvolvendo mais uma ramificação da doença, aquela que me fazia confundir etapas cronológicas. (p. 75).

Dali em diante, não me lembro de mais nada que seja uniforme ou distinto. A especulação acerca dos episódios de amnésia tem uma natureza sádica. Quais bobagens terei proferido? Adormeci ou perdi a consciência? E a mais angustiante delas: fui manietado ou esfaqueei alguém? (p. 135).

Em seguida, recebia dentro da cabeça uma imagem com um som muito peculiar. Mais uma vez o chapisco. Sob aquele som tive mais uma de minhas visões: enxerguei o holandês e seu capanga. (p. 199).

Teorias conspiratórias não podem ocupar nem mais um segundo do meu tempo. (p. 181).

Vivo num labirinto de ideias, como aquelas mensagens espalhadas em garrafas, que flutuam em oceanos que nunca conversam. Desde então, minha missão tem sido justificar minha sobrevivência neste mundo. Agora, forçado pelas circunstâncias, relato os acontecimentos que vivenciei. (p. 28)

O encaixe dos excertos - dispostos aleatoriamente no romance - levam a suposição de que Homero, numa evolução do seu quadro clínico, possa estar incorrendo em delírios e, consequentemente, a trama em que submerge seria parte de um processo inicial de psicose. Todavia, ele mesmo se questiona quanto à veracidade dos acontecimentos: “Todas essas perguntas só mostravam que os acontecimentos não eram só imaginários" (p. 197).

A cena que é o ponto de confluência da trama (o incidente inicial, com o protagonista acordando ensanguentado), por sua vez, pode ser explicada para além das suposições conspiratórias de Montefiore. Em certo momento, o narrador recorda que ao se cortar enquanto folhava um livro, a "sangria fez com que as sinapses submergissem nos hormônios da determinação" (p. 171). Nesse episódio, ele destaca que tinha problemas crônicos de coagulação e que o corte com a folha do livro provocara um grande sangramento. Levando esse aspecto em consideração, pode-se pensar que, no dia em que acordou em seu apartamento, o corte que encontrara em seu pescoço pode ter realmente provocado a abundância de sangue com que se deparou.

Em sua reminiscência não linear, Homero evidencia que na noite que antecedeu tal fato, uma das mulheres que o acompanhara até sua casa, Marly, pediu que ele fizesse a barba com navalha: "mas lâminas no rosto, jamais!”. O narrador salienta que navalhas sempre o ameaçaram (talvez em função do seu problema de coagulação): 
Navalhas pendentes sempre me ameaçaram, mas não me lembrava de ter largado, no balcão de mármore preto, aquele canivete aberto, equilibrado. Aquilo tinha um nome e estava descrito nos livros de psicopatologia: "consciência objetal". Isso ocorre quando a mera consciência da presença de um objeto afeta sensorialmente uma pessoa.

(...) Foi aí, exatamente, que o enredo veio à tona de uma vez, com uma consciência súbita acompanhada de um barulho áspero na cabeça. (...) Senti que o cenário tinha todos os elementos de uma farsa e o diagnóstico se completou: era um teatro, e fora encomendado para me incriminar. (p. 22).

O sangue, as navalhas e o barulho em sua cabeça fazem submergir o teatro de encenação que, muito provavelmente, fora criado por sua "chave dupla onírica", o estado mental peculiar a que o narrador se refere para ensejar seu relato. Navalhas pendentes, portanto, apresenta uma narrativa fragmentária que, aliada ao enredo, abalam a perspectiva do leitor, imprimindo a vertigem do texto e da personagem ao ato de leitura que também necessita de idas e vindas para tentar reconfigurar a história, sem, contudo, preencher as questões que permanecem em aberto, longe de qualquer certeza apaziguadora.

\section{REFERÊNCIAS}

KAFKA, Franz. O processo. Tradução e posfácio Modesto Carone. São Paulo: Companhia das Letras, 2005.

ROSENBAUM, Paulo. Navalhas pendentes. Belo Horizonte: Caravana Grupo Editorial, 2021.330 p.

WALDMAN, Berta. [Epígrafe Editora Filamentos]. In.: ROSENBAUM, Paulo. Navalhas pendentes. Belo Horizonte: Caravana Grupo Editorial, 2021.p. 15. 